\title{
A SPERM TAIL DEFECT ASSOCIATED WITH INFERTILITY IN A GOAT - CASE REPORT
}

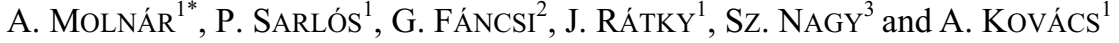 \\ ${ }^{1}$ Research Institute for Animal Breeding and Nutrition, H-2053 Herceghalom, \\ Gesztenyés u. 1-3, Hungary; ${ }^{2}$ Department of Animal Breeding, Nutrition and Laboratory \\ Animal Science, Faculty of Veterinary Science, Szent István University, Budapest, \\ Hungary, ${ }^{3}$ Institute of Animal Breeding, Faculty of Agricultural Sciences, University \\ of West-Hungary, Mosonmagyaróvár, Hungary
}

(Received February 26, 2001; accepted May 17, 2001)

\begin{abstract}
Semen of an infertile Dutch White (Saanenthal) goat buck was examined. Light and electron microscopic examinations showed aberrations of the sperm tails resembling the so-called Dag or Dag-like defects described in several cattle breeds. Ejaculated semen showed that virtually all of the cells had strongly coiled or broken tails, or fractured midpieces. Ultrastructural investigations by transmission electron microscopy (TEM) showed uneven distribution of the mitochondria in the midpiece. Coiled tails were encapsulated by a common membrane, and dislocated axial fibres and different membranous structures were also present. The ultrastructural characteristics of the defective sperm tails, the missing parts of the axial fibre bundle and the misalignment of the mitochondria indicate that this first case reported in goat is similar to the Dag-like defect in cattle.
\end{abstract}

Key words: Goat sperm, tail defect, light and electron microscopy

The characteristic features of the so-called 'Dag' or 'Dag-like' defect are multiple fractures of the axonemal fibres in the midpiece and mitochondrial sheath disruption. The defect may be found in a few sperm cells due to a disturbance of spermatogenesis in any cattle breed; however, it has been shown to be inherited via a recessive gene in the Jersey breed and appears to have a heritable basis in the Hereford breed as well. When a bull has both recessive genes, 60 $100 \%$ of sperm cells will be affected (Barth, 1994).

Barth and Oko (1989) discussed the possible mechanisms of this defect as (a) weakness of the outer dense fibres caused by zinc excess, (b) premature release of hydrolytic enzymes from the distal cytoplasmic droplet, and (c) malformation of the mitochondrial sheath.

Andersen Berg et al. (1996) emphasise the difference between 'Dag' and 'Dag-like' defect: the misalignment of mitochondria and the malformation of the axial fibre bundle are the typical structural characteristics of the 'Dag-like' de-

*Corresponding author; E-mail: amolnar@atk.hu; Fax: +36 (23) 319-133 
fect, while no such structural changes were reported in the 'Dag' defect, described in Jersey bulls. On the other hand, Barth and Oko (1989) mention the possibility that these structural changes were unnoticed in Jersey bulls. These abnormalities were not described in goat.

In this study we tried to find the ultrastructural cause of immotility of the sperm cells of an infertile goat buck.

\section{Materials and methods}

A one and half year old horned Dutch White (Saanenthal) goat buck was reported to be infertile by the owner. The buck was kept together with 12 females but had no offspring in 1998 and in 1999 either. He was in good physical condition, and showed normal sexual behaviour including mating. Visual investigation of the external genital organs showed no abnormalities.

In May 2000 two ejaculates were collected at a 2-week interval by the use of an artificial vagina. Parameters like volume and concentration were recorded.

After castration, samples from the rete testis, caput, corpus and cauda epididymidis and from the vas deferens were washed with $0.9 \% \mathrm{NaCl}$ solution.

Samples from the testes and from different parts of the epididymides were taken and fixed in 5\% neutral formaldehyde for histological investigations.

Chromosome investigation was carried out from peripheral blood cultures according to Moorhead et al. (1960).

\section{Light microscopy}

Semen smears for light microscopic evaluation were stained by the method of Kovács and Foote (1992).

The trypan blue-Giemsa stained smears were evaluated in a LeitzOrthoplan light microscope, under oil immersion at $\times 1250$ magnification. Two hundred cells per slide were counted and evaluated for tail morphology (Barth and Oko, 1989) and membrane integrity (Nagy et al., 1999) as intact tails, rough mitochondrial sheath and coiled or broken tails.

\section{Scanning electron microscopy (SEM)}

Semen samples were fixed in $4 \%$ paraformaldehyde and dried at $37{ }^{\circ} \mathrm{C}$ in a thermostat. Dried samples were put into phosphate buffer for $10 \mathrm{~min}, 2 \%$ osmium tetroxide for $20 \mathrm{~min}$ and phosphate buffer for $5 \mathrm{~min}$. Samples were dehydrated in an ascending series of alcohol, then dried at $56{ }^{\circ} \mathrm{C}$ in a thermostat. Dried samples were placed and fixed on blocks by Dotile glue, metallised with $15 \mathrm{~nm}$ gold and examined in a JEOL JSM-35 scanning electron microscope. 


\section{Transmission electron microscopy (TEM)}

Semen samples were fixed in $4 \%$ paraformaldehyde, mixed with $3 \%$ agar. One $\mathrm{cm}^{3}$ cubes were postfixed in $4 \%$ paraformaldehyde for $1 \mathrm{~h}$, rinsed in buffer solution for $2 \mathrm{~h}$, fixed in 2\% osmium tetroxide, dehydrated in ascending alcohol solution, and embedded in Durcupan ACM. The ultra-thin sections were doublestained with uranyl acetate and lead citrate for 10 and $5 \mathrm{~min}$, respectively, and examined in a JEOL $100 \mathrm{~S}$ transmission electron microscope.

\section{Histological analysis}

Samples for histological examinations were stained according to the method of Endes (cit. Krutsay, 1980) and with haematoxylin and eosin. Specimens were examined by light microscope, under oil immersion, at $\times 1250$ magnification.

\section{Results}

The different parameters of the two ejaculates of the buck, like volume, $\mathrm{pH}$, cell concentration, etc. were normal, while there was no mass movement of the cells (Table 1).

Table 1

Parameters of the two ejaculates

\begin{tabular}{ccccc}
\hline Ejaculate & Volume $(\mathrm{ml})$ & $\begin{array}{c}\text { Concentration } \\
\left(\times 10^{9} / \mathrm{ml}\right)\end{array}$ & $\mathrm{pH}$ & $\begin{array}{c}\text { Motility } \\
(\%, \text { assessed visually })\end{array}$ \\
\hline 1 & 1.3 & 3.1 & 6.8 & 0 \\
2 & 1.5 & 2.9 & 6.9 & 0 \\
\hline
\end{tabular}

Neither histological analysis of the testes and epididymides nor chromosome investigation showed aberrations.

Light microscopic investigation of the ejaculated semen showed that virtually all of the cells had strongly coiled or broken tails or fractured midpiece. Coiled tails usually had intact membrane (unstained tails, according to Nagy et al., 1999) but coiled tails with stained-broken membrane were also seen (Fig. 1). SEM investigations showed the same phenomenon: in Fig. 2a, the coiled tails have intact cell membrane, while in Fig. $2 b$, the membrane of the tail is broken and the axial fibres are freed. 


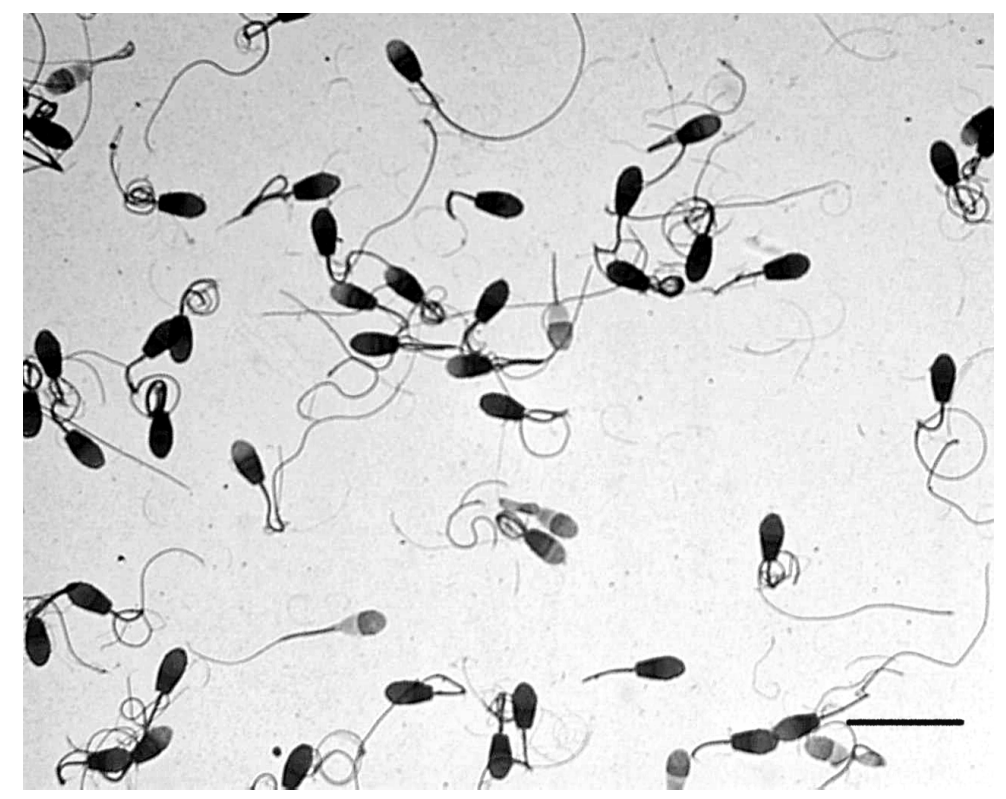

Fig. 1. Light microscopic picture of the semen of the goat - virtually all sperm cells are abnormal. Bar $=20 \mu \mathrm{m}$

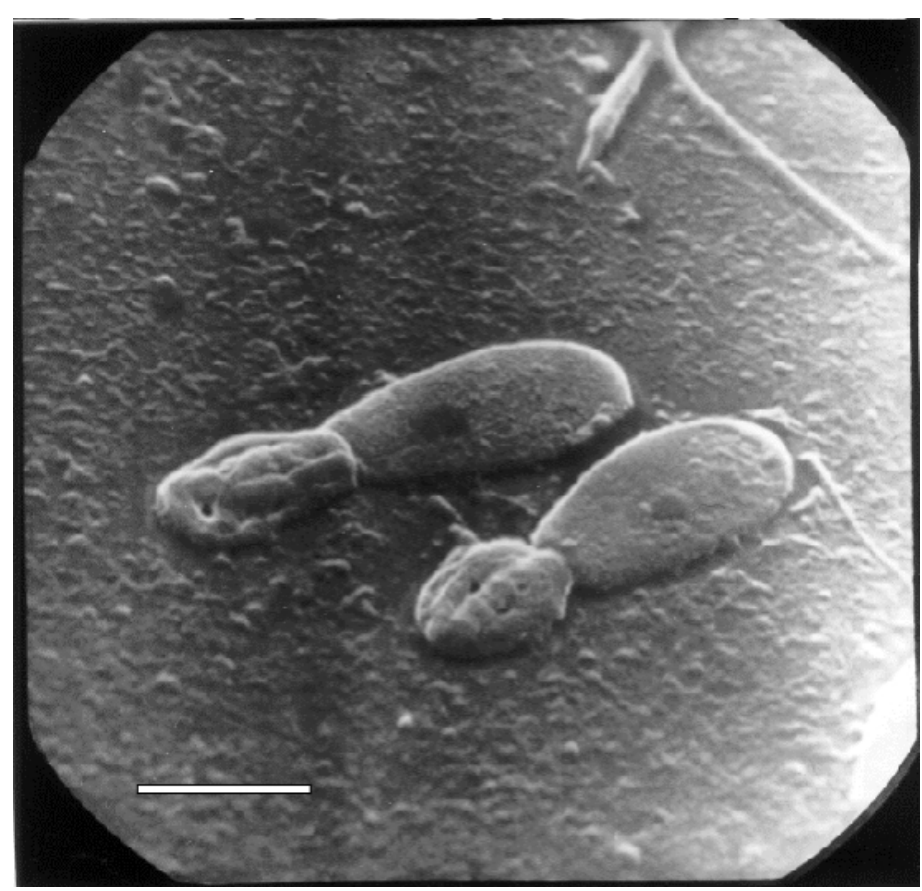

Fig. 2a. Two cells with strongly coiled tail and intact tail membrane. SEM. Bar $=5 \mu \mathrm{m}$ 


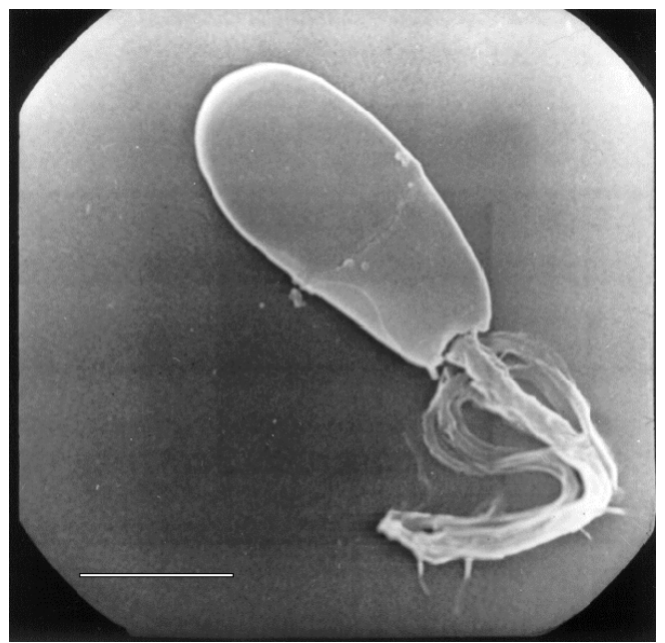

Fig. $2 b$. Sperm cell with strongly coiled tail and disrupted tail membrane. SEM. Bar $=5 \mu \mathrm{m}$

Ultrastructural investigations by TEM showed the uneven distribution of the mitochondria in the midpiece (Fig. 3a). In Fig. 3b, the larger group of fibres in the axonemal complex, namely axial fibres 4, 5, 6 and 7 (including both axonemal doublets and outer dense fibres) are missing. The coiled tail is encapsulated by a common membrane, dislocated axial fibres and different membranous structures are also present. In Fig. 3c, the same axonemal malformation can be seen at larger magnification. Occasionally only central microtubules and axial fibres 2, 3 and 8 are present (Fig. 3d, arrow).

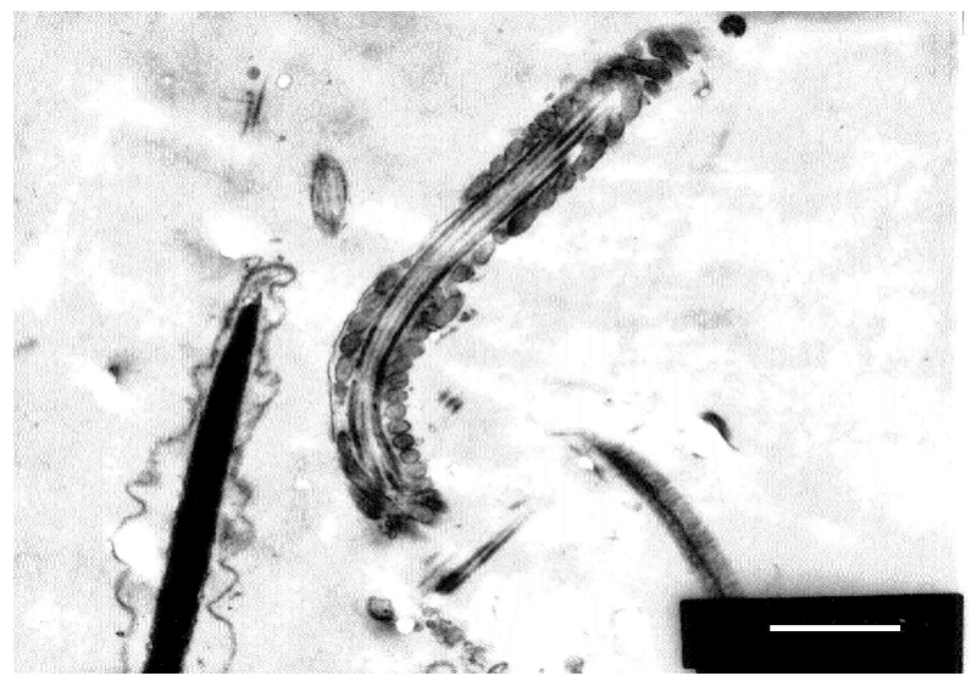

Fig. 3a. TEM picture shows the uneven distribution of the mitochondria in the midpiece. $\mathrm{Bar}=1 \mu \mathrm{m}$ 


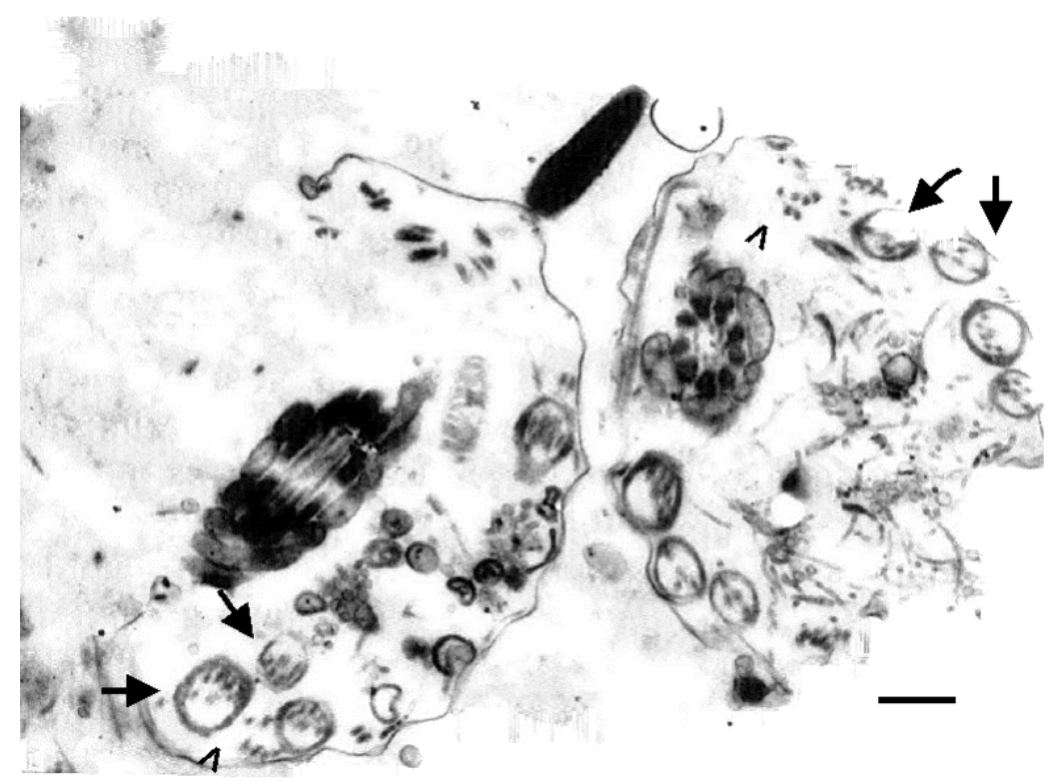

Fig. 3b. Coiled tails encapsulated by a common membrane. Note the incomplete axonemal structure (arrows) and dislocated axonemal fibres (arrowheads). TEM. Bar $=0.5 \mu \mathrm{m}$

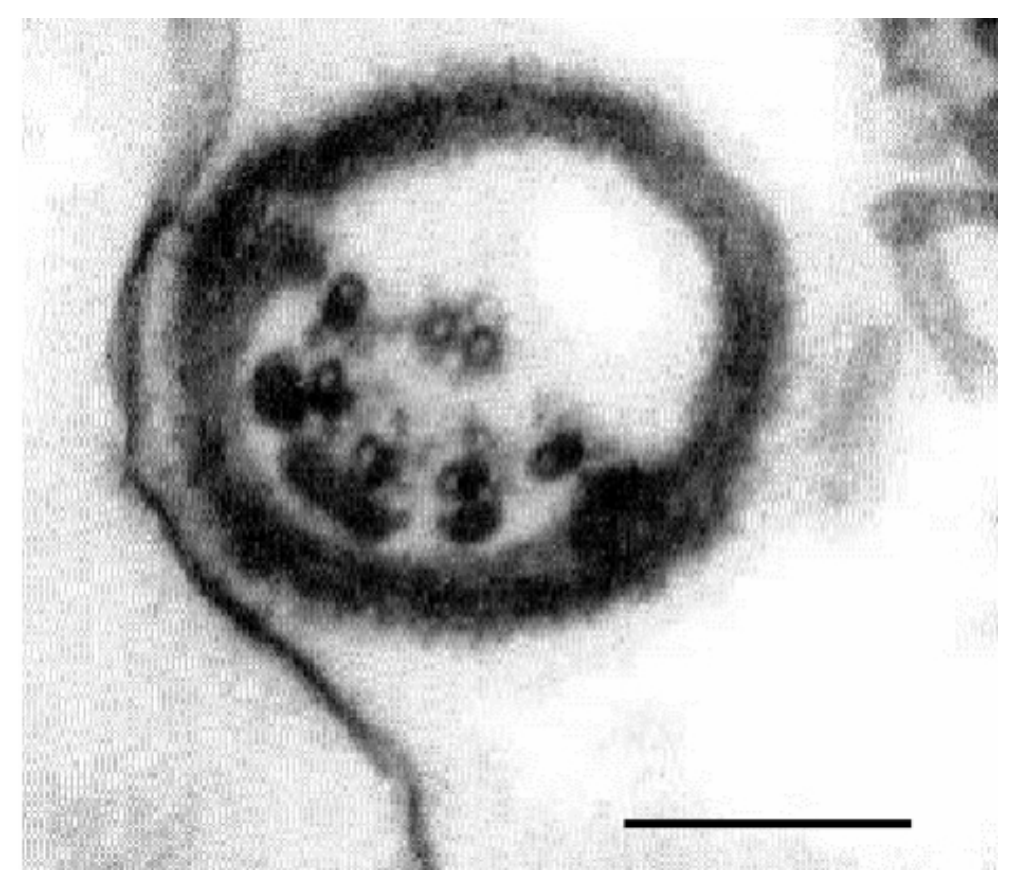

Fig. 3c. TEM photograph of an incomplete axoneme. Axial fibres 4, 5, 6 and 7 are missing. $\mathrm{Bar}=0.2 \mu \mathrm{m}$ 


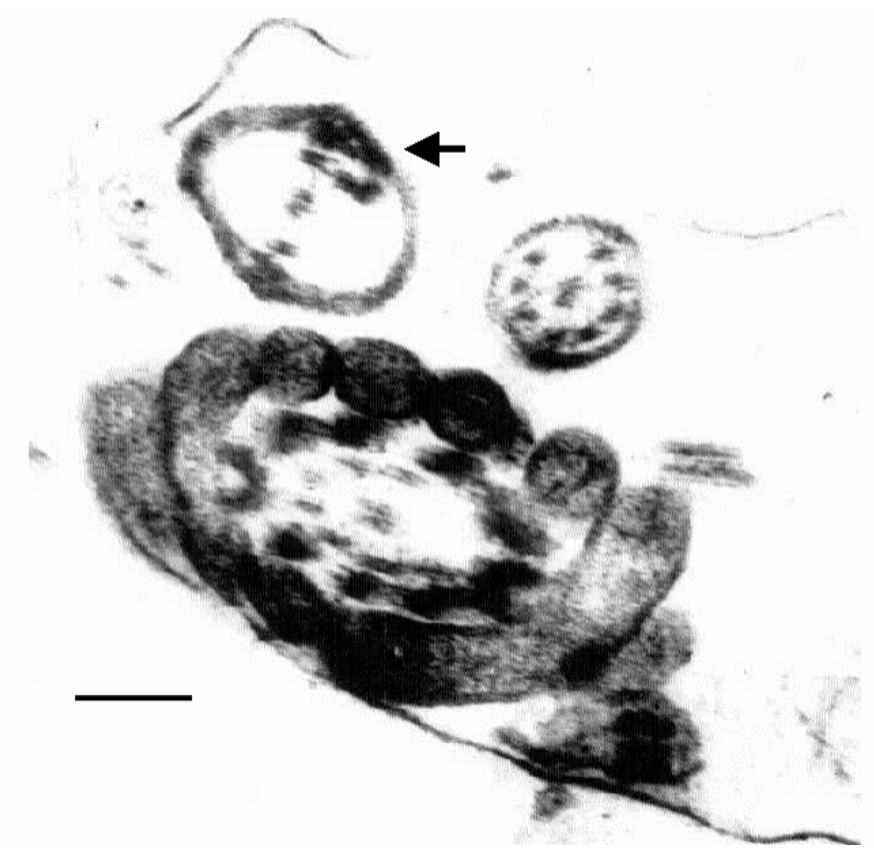

Fig. $3 d$. Arrow shows a more severe form of the abnormality: only central microtubules and axial fibres 2,3 and 8 are present. TEM. Bar $=0.2 \mu \mathrm{m}$

Results of the light microscopic evaluation of the samples washed from different parts of the reproductive tract are presented in Table 2.

\section{Table 2}

Incidence (\%) of the different structural features of spermatozoa from different parts of the reproductive tract

\begin{tabular}{lcccccc}
\hline \multicolumn{1}{c}{ Feature } & Testis & Caput ep. & Corpus ep. & Cauda ep. & Vas deferens & Ejaculate \\
\hline $\begin{array}{l}\text { Intact tail } \\
\text { Rough mitochondrial }\end{array}$ & 70.5 & 41.2 & 13.4 & 7.4 & 5.5 & 5.0 \\
sheath & 17.5 & 18.0 & 11.8 & 6.2 & 6.0 & 7.0 \\
Coiled or broken tail & 12.0 & 40.8 & 74.8 & 86.4 & 88.5 & 88.0 \\
\hline
\end{tabular}

\section{Discussion}

The ultrastructural characteristics of the defective sperm tails, the missing parts of the axial fibre bundle and the misalignment of the mitochondria indicate that this defect can be classified as 'Dag-like' defect reported previously in several cattle breeds (Andersen Berg et al., 1996). 
Barth and Oko (1989) suggest that the coiling of the tails and the dislocation of the axial fibres may be due to malformation of the mitochondrial sheath in late spermatogenesis. The increase in coiling, folding and fracturing of the midpiece during the epididymal transit may be a result of the gaining of motility of the axoneme. Our findings support this idea as the incidence of the defective cells became higher and higher in samples from successive parts of the epididymis.

It was suggested (Blom, 1966, cit Barth and Oko, 1989) that this defect was due to a recessive heritable condition. We had the possibility to check the semen of a half-sib of this goat. Although the animal was immature, his semen had a good quality and did not contain such defective cells. In the near future we plan to find more relatives following the pedigree of the goat and investigate the heritability of this sperm defect.

\section{Acknowledgements}

The authors wish to acknowledge the excellent technical assistance provided by Mrs. Cs. Drén and Mrs. P. Szilágyi in scanning and transmission electron microscopy and in histological examinations.

\section{References}

Andersen Berg, K., Filseth, O. and Engeland, E. (1996): A sperm midpiece defect in a Hereford bull with variable semen quality and freezability. Acta Vet. Scand. 37, 367-373.

Barth, A. D. (1994): Bull breeding soundness evaluation. Western Canadian Association of Bovine Practitioners, Saskatoon, SK, Canada, 68 pp.

Barth, A. D. and Oko, R. J. (1989): Abnormal morphology of bovine spermatozoa. Iowa State University Press, Ames, IA, USA, 285 pp.

Kovács, A. and Foote, R. H. (1992): Viability and acrosome staining of bull, boar and rabbit spermatozoa. Biotech. Histochem. 67, 119-124.

Krutsay, M. (1980): Histological Techniques (in Hungarian). Medicina Kiadó, Budapest.

Moorhead, P. J., Nowell, P. C., Mellmann, W. J., Battips, D. A. and Hungerford, D. A. (1960): Chromosome preparation of leucocytes cultured from human peripheral blood. Exp. Cell Res. 20, 613-616.

Nagy, Sz., Házas, G., Bali Papp, Á., Iváncsics, J., Szász, F., Szász, F. Jr., Kovács, A. and Foote, R. H. (1999): Evaluation of sperm tail membrane integrity by light microscopy. Theriogenology 52, 1153-1159. 